\title{
Author Reply
}

\section{Lauren M. Maloney, MD, NRP, FP-C, NCEE; ${ }^{1}$ C Vladimir Kotelnik, MD $;^{1}$ Kevin Pesce, EMT-P; ${ }^{1}$ William M. Masterton, EMT-P; ${ }^{2}$ Robert T. Marshall, MD, FACEP, FAEMS; ${ }^{1}$ Gregson Pigott, MD; ${ }^{2}$ Nathaniel Bialek, BS, EMT-P, CCHP, ${ }^{2}$ Jason Winslow, MD ${ }^{2}$}

1. Department of Emergency Medicine, Stony Brook University Hospital, Stony Brook, New York USA

2. Suffolk County Department of Health Services, Yaphank, New York USA

\section{Correspondence:}

Lauren Maloney, MD

Stony Brook University Hospital

Dept. of Emergency Medicine

HSC Level 4 Room 050

Stony Brook, New York 11794-8350 USA

E-mail: lauren.maloney@stonybrookmedicine.edu

Conflicts of interest: none

Keywords: 12-lead electrocardiogram; Emergency Medical Services; emergency medical technician; prehospital; STEMI

Received: April 16, 2021

Accepted: April 23, 2021

doi:10.1017/S1049023X21000480

(C) The Author(s), 2021. Published by

Cambridge University Press on behalf of the

World Association for Disaster and Emergency

Medicine.
Maloney LM, Kotelnik V, Pesce K, Masterton WM, Marshall RT, Pigott G, Bialek N, Winslow J. Author Reply. Prehosp Disaster Med. 2021;36(4):500.

\section{Dear Editor,}

We thank the authors of the submitted Letter to the Editor ${ }^{1}$ for their interest in our $\operatorname{article}^{2}$ and would like to offer a Letter of Reply to their inquiries.

As described in the second paragraph of the Results section, ${ }^{2}$ as well as the in the title for Table $1,{ }^{2}$ this table displays the time intervals for calls which had a full set of times available. While advanced statistical analysis would be ideal in describing these times, it was not within the scope or purpose of this retrospective study, and as such, data are presented using the $25^{\text {th }}, 50^{\text {th }}$, and $75^{\text {th }}$ percentiles. Furthermore, while time between first medical contact and time to primary coronary intervention would certainly be interesting to examine, those data were not available for analysis.

It is not particularly clear to us what "average time spent on imaging" is referring to. The number which is cited in the Letter to the Editor is the time that Emergency Medical Service crews spent on scene, and while that does include acquiring and transmitting a 12-lead electrocardiogram, it also encompasses getting to the patient, assessing and treating the patient, packaging the patient for transport, and moving the patient to the ambulance. As such, the authors of the Letter to the Editor seem to suggest an incorrect assumption regarding what they deem to be a "delay seen in the first imaging."

References

1. Kuas C, Canakci ME. The effect of prehospital ECGs on patient care in STEMI. Prehosp Disaster Med. In Press.

2. Kotelnik V, Pesce K, Masterton WM, et al. 12-lead electrocardiograms acquired and transmitted by emergency medical technicians are of diagnostic quality and positively impact patient care. Prehosp Disaster Med. 2021;36(1):47-50. 